\title{
Enhancement of properties of pure lead via underwater friction stir processing for thermoelectric and battery applications
}

\author{
C. Sekkappan, V. Valsaraj, A. K. Lakshminarayanan* \\ Department of Mechanical Engineering, SSN College of Engineering, Kalavakkam, Chennai - 603110, Tamil Nadu, India
}

Received 27 February 2019, received in revised form 25 May 2019, accepted 19 June 2019

\begin{abstract}
In this work, friction stir processing of pure lead metal was performed with various processing parameters and with the varied environment (air and underwater) to investigate the effect of the processing on the microstructure, mechanical and thermal properties. The results showed that the underwater processed samples had a more refined grain structure than those processed in air. The least grain size of $5 \mu \mathrm{m}$ was seen in the sample processed underwater with a rotational speed of $900 \mathrm{rpm}$ (S09) which was the optimum condition. The optimum condition for samples processed in the air was the $650 \mathrm{rpm}$ rotational speed (S03) which revealed the grain size of $12 \mu \mathrm{m}$. The tensile strength of the sample S09 increased by $141.94 \%$ from the base metal value while it increased by $77.33 \%$ for the sample S03. The thermal conductivity of the sample S09 decreased by $59.92 \%$ from the base metal value while it decreased by $39.48 \%$ for the sample S03.
\end{abstract}

Key words: underwater friction stir processing, lead, microstructure, tensile strength, thermal conductivity, Zener-Hollomon parameter

\section{Introduction}

Lead is an interesting material which is soft but highly dense. It is extensively used in lead-acid batteries as an electrode plate [1]. However, owing to its poor mechanical strength, it is not used in its purest form. Generally, it is alloyed with antimony, calcium, and selenium to increase its mechanical strength. However, high alloying amount of antimony leads to higher hydrogen evolution, which also accelerates the ageing process of the battery [2]. So, considerable improvement in the mechanical strength of pure lead is required to use it directly in lead-acid batteries. Its strength can be enhanced by reducing the grain size, which is done by introducing severe plastic deformation [3-8]. Lead acid batteries have a relatively large power-to-weight ratio [9] and along with their low cost make them an attractive option over other types of batteries [10]. So, its production is expected to increase in the upcoming years.

A thermoelectric (TE) material generates electricity while in a temperature gradient [11]. These materials are capable of scavenging and converting waste heat generated by other power generation methods. Nowadays, lead has been paid extensive attention in the thermoelectric community to use it as a TE base material because its electric conductivity is high and its thermal conductivity is relatively less among metals, which is the major requisite for good thermoelectric material. TE performance depends both on the temperature gradient across the material $(\Delta T)$ and on the efficiency of the conversion of the temperature gradient to the potential gradient which is evaluated by the thermoelectric figure of merit, ZT, (Eq. (1)):

$$
\mathrm{ZT}=S^{2} \sigma T / k_{\mathrm{tot}}
$$

where $S$ is the Seebeck coefficient, $T$ is the absolute temperature, $\sigma$ is the electrical conductivity, and $k_{\text {tot }}$ is the total thermal conductivity $[12,13] . k_{\text {tot }}$ is a combination of the thermal energy transported by charge carriers $\left(k_{\mathrm{el}}\right)$ and the lattice thermal energy transported by phonons $\left(k_{\text {lat }}\right)$. To develop $\mathrm{Pb}$ as a good TE material, its thermal conductivity should be reduced. The lattice thermal conductivity $\left(k_{\text {lat }}\right)$ of the metal can be reduced, without affecting the electrical

*Corresponding author: +91 4427469700 ext.: 236; fax: +91 44 27469772;

e-mail addresses: LakshminarayananAK@ssn.edu.in, akln2k2@yahoo.com 
conductivity, by reducing the grain size. This can be done by subjecting it to severe plastic deformation. In addition to this, the Seebeck coefficient of lead metal remains constant over a range of temperature, which is an added advantage.

Lead is the most toxic heavy element in the environment. Human exposure to lead can cause neurotoxicity. It damages the nervous system and causes brain disorders [14]. Thus, it is essential to protect industrial workers from lead exposure and its fatal effects. Standard conventional processing of lead and its alloys is an environmental concern due to the toxic effects of the fumes released. Inhalation of toxic fumes evaporated from the lead metal during such processes is extremely unsafe. Moreover, any conventional processing of lead metal, fusion welding, for example, is unsatisfactory and substandard. Therefore, it is beneficial to utilize solid-state processing techniques since it does not release toxic fumes and gives satisfactory results.

Friction stir processing (FSP), which is a solidstate processing method, has received great attention for producing severe plastic deformation in the last few years [15]. FSP is a thermo-mechanical process, in which both the mechanical and the thermal aspects are controlling the process, which in turn controls the resulting microstructure of the material to achieve specific and desired mechanical properties [1618]. Darras et al. [19] performed the FSP on commercial AZ31B-H24 magnesium alloy sheets and found that FSP leads to finer and more homogenized grain structure. Yang [20] reported that the improvement in the tensile performance of dual-phase $\mathrm{Mg}-8.5 \mathrm{Li}-2.8 \mathrm{Al}-$ $-01.1 \mathrm{Zn}$ alloy FSP is mainly due to the refinement of $\alpha-\mathrm{Mg}$ phase and $\beta$-Li phase and solid solution strengthening. Alavi Nia et al. [21] studied the effects of an overlapping multi-pass FSP on AZ31 magnesium alloy and found that the mechanical strength was increased in the process direction. Raja et al. [22] mentioned that the multipass FSP on as-cast AZ91 magnesium alloy could effectively improve its tensile properties. Huang et al. [23] FSPed the Mg-Zn-Y-Zr alloy and found an enhancement in its mechanical properties. The improvement in the mechanical properties of the magnesium alloys by FSP was mainly attributed to grain refinement. In FSP, dynamic recrystallization is responsible for the grain refinement. However, grain growth is also observed while exposing the processed material to a high temperature for a specified period. By minimizing grain growth, increased grain refinement is achieved.

Underwater friction stir processing (UFSP) is one of the promising methods in which the FSP is wholly conducted inside the water container, which acts as a coolant. It has drawn much attention of late for processing and repair of wet structures. This technique can minimize processing defects, stress corrosion cracking susceptibility, and residual hydrogen level in comparison with conventional methods [24, 25]. Moreover, a high cooling rate under water avoids dissolution and coarsening of strengthening phases [26]. In 2005, Douglas and Kenneth [27] were the first to study UFSP. It has been demonstrated to be a simple, effective, and economical technique for grain refinement. Chai et al. [28] reported that the average grain size of UFSP AZ91 was $1.2 \mu \mathrm{m}$, which was much finer than that of normal FSP conducted in the air $(7.8 \mu \mathrm{m})$. Basil et al. [29] also demonstrated that the average grain size of AZ31 attained were 18.9, 15.9, and 13.3 $\mu \mathrm{m}$ for FSP in air, submerged in hot water and submerged in cold water, respectively. Bhadouria et al. [30] found a significant reduction in grain size $(28.7$ and $13.1 \%$ ) and increase in micro-hardness (14.55 and $8.92 \%$ ) along depth and width of stir zone (SZ) of UFSPed specimen as compared to normal FSPed specimens. Cao et al. [31] conducted UFSP on Mg-Y-Nd cast alloy to obtain the finest grain size of $1.1 \mu \mathrm{m}$ under a UFSP parameter of $600 \mathrm{rpm}$ and $60 \mathrm{~mm} \mathrm{~min}^{-1}$ due to the lowest heat input. Feng et al. [32] reported that the ultra-fine grains obtained by UFSPing the aluminium alloy 2219-T6 are less than $1 \mu \mathrm{m}$ and the area fraction of ultra-fine grains increases as the rotational tool speed (heat input) decreases.

Though lead is used in a variety of applications, there is a very limited study on the processing of lead. Gunen et al. [33] friction stir welded the pure lead metal and obtained an optimum joint at a rotational speed of $1500 \mathrm{rev}^{-1} \mathrm{~min}^{-1}$ and transverse tool speed of $100 \mathrm{~mm} \mathrm{~min}^{-1}$. In this investigation, pure lead metal was subjected to FSP in air and underwater (UFSP). The main aims of this research were (i) to conduct a comparative study among the base metal, FSPed, and UFSPed samples processed under various rotational speeds. They were compared based on the macrostructure, microstructure, defects, tensile strength, and thermal conductivity; (ii) to find the optimum parameter and environment for the thermoelectric and battery application; (iii) to obtain the relationship between Zener-Hollomon parameter and the grain size.

\section{Experimental procedure}

In the present research, pure lead metal with $5 \mathrm{~mm}$ thickness was subjected to FSP. The welding pitch, which is the ratio of the rotational speed to transverse speed from the work of Gunen et al. [33], was noted. To establish the feasible limits of the process parameters, the process was performed for a wide range of rotational speed. To keep the average welding pitch of all processes closer to the optimum welding pitch obtained by Gunen et al. [33], the transverse tool speed $(v)$ was kept constant at $50 \mathrm{~mm} \mathrm{~min}^{-1}$ for all the pro- 
Table 1. Establishing feasible limits of process parameters

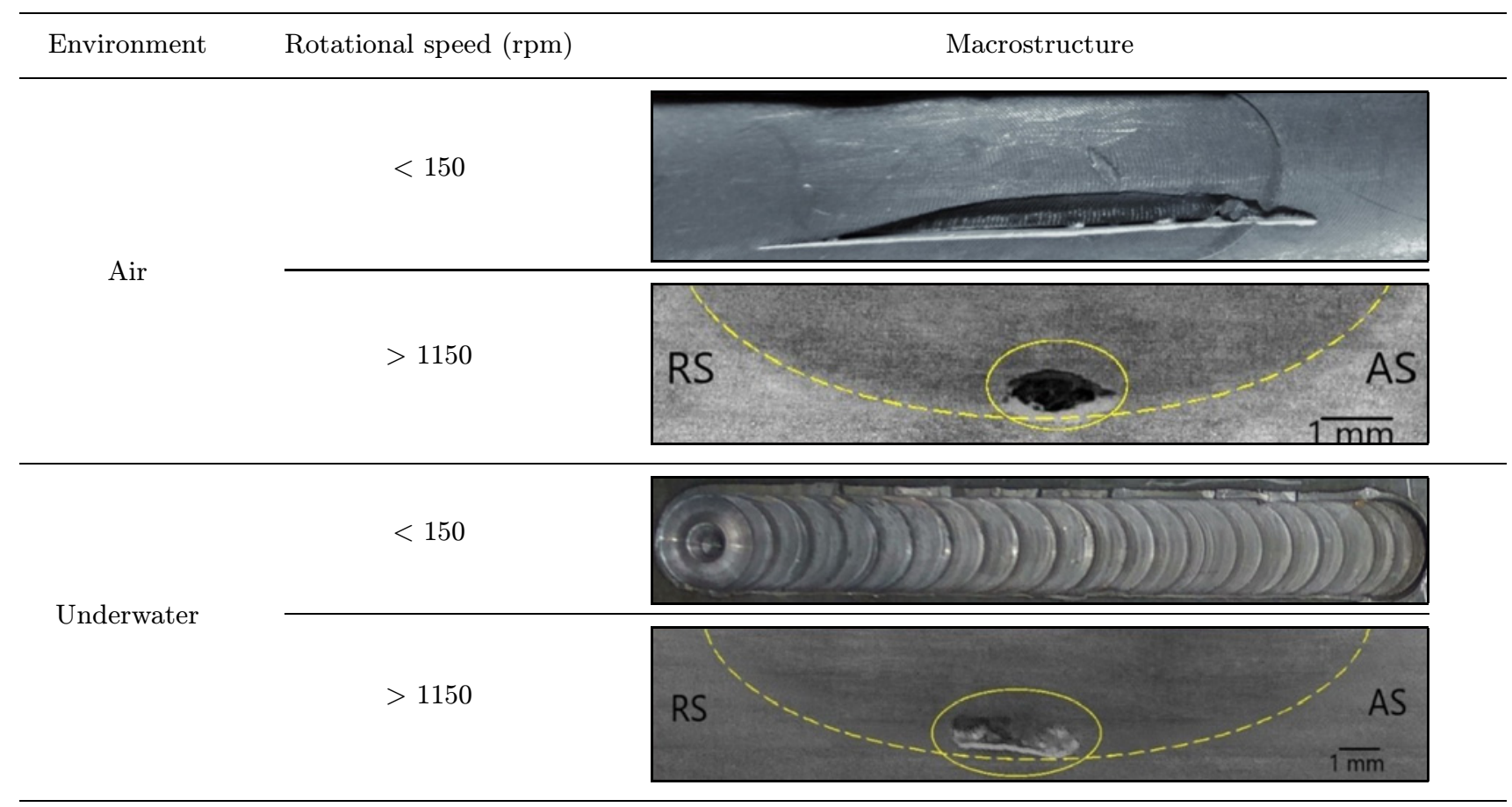

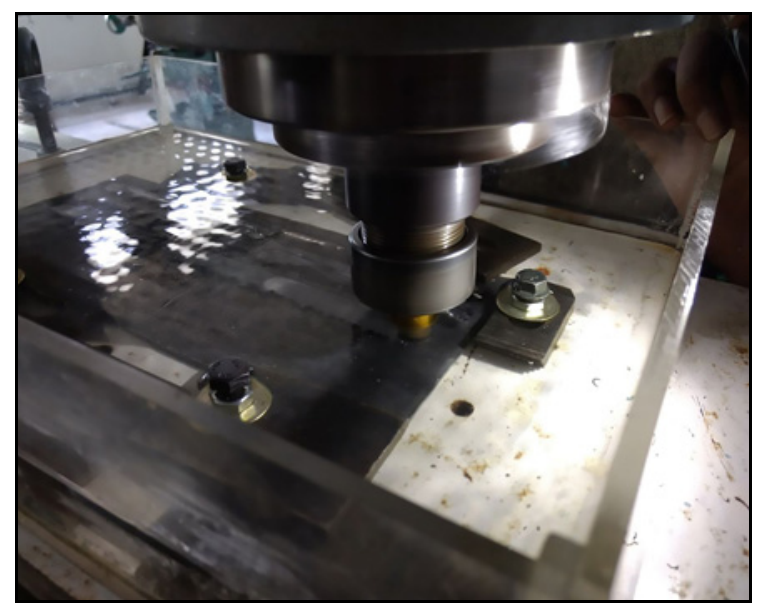

Fig. 1. Underwater setup.

cessed samples. The thickness and the manufacturing process of the lead plate and the profile of the processing tool varied from the work of Gunen et al. [33]. This was also considered before finalizing the transverse tool speed. Another reason for keeping the transverse speed constant was to study the full effect of the rotational speed on the microstructure, tensile strength, and thermal conductivity of the samples processed. A cylindrical tool with a shoulder diameter of $15 \mathrm{~mm}$ and a probe diameter of $6 \mathrm{~mm}$ was used for FSP. The tool was tilted at an angle of $1.5^{\circ}$ from normal direction concerning the processed workpiece.

Initially, two metal plates with dimensions of
$150 \times 100 \times 5 \mathrm{~mm}^{3}$ were ground using 800 grit $\mathrm{SiC}$ papers and cleaned with acetone. One of the prepared metal plates was then processed in an air environment with varying rotational speeds. Then, the other plate was clamped in a container which was made of steel at the bottom, and its surrounding walls were made of acrylic. Water was poured into the container to fully immerse the metal plate. With this setup (Fig. 1), the plate was processed in submerged conditions for the same range of rotational speeds.

The practical limits were finalized based on visual inspection of defects, as summarized in Table 1. The rotational speed had a major effect on the process quality. The groove defect was found at the beginning of the weld on the samples processed at a rotational speed less than $150 \mathrm{rpm}$ in air. The reason for this defect is insufficient heat input during the process. The sample processed in the air at a rotational speed higher than $1150 \mathrm{rpm}$ had pinhole defects. These pinhole defects are found due to abnormal stirring. The samples processed underwater with a rotational speed less than $150 \mathrm{rpm}$ had a rough surface, which is due to insufficient plastic flow. Void defect or the wormhole defect was found on the sample processed underwater at a rotational speed higher than $1150 \mathrm{rpm}$. This may be due to excess heat and poor material mixing. The presence of a void reduces the strength of the process sample [34]. The finalized processing parameters and sample numbers for each sample are represented in Table 2 .

All the specimens were cross-sectioned perpendicular to the processing direction and then polished using 
Table 2. Processing parameters of the samples

\begin{tabular}{ccc}
\hline Rotational speed $(\mathrm{rpm})$ & Air & Underwater \\
\hline 150 & $\mathrm{~S} 01$ & $\mathrm{~S} 06$ \\
400 & $\mathrm{~S} 02$ & $\mathrm{~S} 07$ \\
650 & $\mathrm{~S} 03$ & $\mathrm{~S} 08$ \\
900 & $\mathrm{~S} 04$ & $\mathrm{~S} 09$ \\
1150 & $\mathrm{~S} 05$ & $\mathrm{~S} 10$ \\
\hline
\end{tabular}

an electrolytic polishing machine. The cross-sectioned sample, initially polished up to 1500 grit $\mathrm{SiC}$ papers was connected to the anode. $99.99 \%$ glacial acetic acid $(1000 \mathrm{ml})$ and $30 \%$ hydrogen peroxide solution $(500 \mathrm{ml})$ in the ratio of $2: 1$ at ambient temperature were used as the electrolyte. The voltage was maintained at $40 \mathrm{~V}$, and the current flowing through the electrolyte was found to be $0.03 \mathrm{amps}$. The microstructures of the samples were analyzed using optical microscopy. The thermal diffusivity of all the processed samples was found using the laser flash analysis (LFA) equipment (LFA 447 Nanoflash, NETZCH, Germany) at room temperature. The error in thermal diffusivity measurement on Netzsch LFA-447 is within $\pm 3 \%$. The specific heat was measured by the Differential Scanning Calorimetry (DSC) apparatus (NETZSCH DSC 204 F1). The accuracy of this apparatus was found to be within $\pm 5 \%$. The total thermal conductivity was obtained from the relation (Eq. (2)):

$$
k_{\text {tot }}=D C_{\mathrm{p}} \rho,
$$

where $D$ is thermal diffusivity, $C_{\mathrm{p}}$ is specific heat, and $\rho$ is the density of the sample. The tensile strength of samples was measured according to modified ASTM E8 standards using a universal tensile testing machine. Since the effective stir region of the processed samples after machining was around $3-4 \mathrm{~mm}$, the modified ASTM E8 standards were used. The schematic of the tensile test specimen and the image of samples after the tensile test are shown in Fig. 2. The temperature during FSP was measured with a data acquisition system using $\mathrm{K}$ type thermocouples embedded on the centreline just outside the processing zone. The temperature was noted throughout the processing, and the peak temperature was taken as the processing deformation temperature $(T)$.

\section{Results and discussion}

\subsection{Macrostructure}

Figures 3a,c show the top view of the sample processed with the maximum rotational speed in air (S5) and underwater (S10) environment, respectively. Figures $3 \mathrm{~b}, \mathrm{~d}$ show the cross-section of the sample S5 and

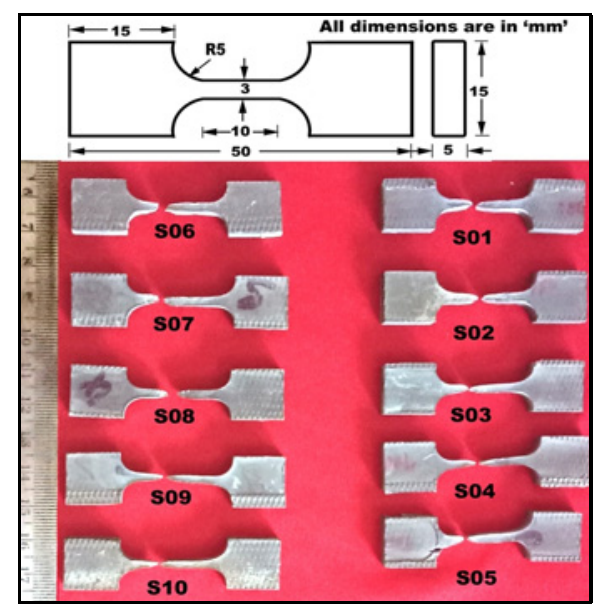

Fig. 2. Schematic and fractured tensile specimen.

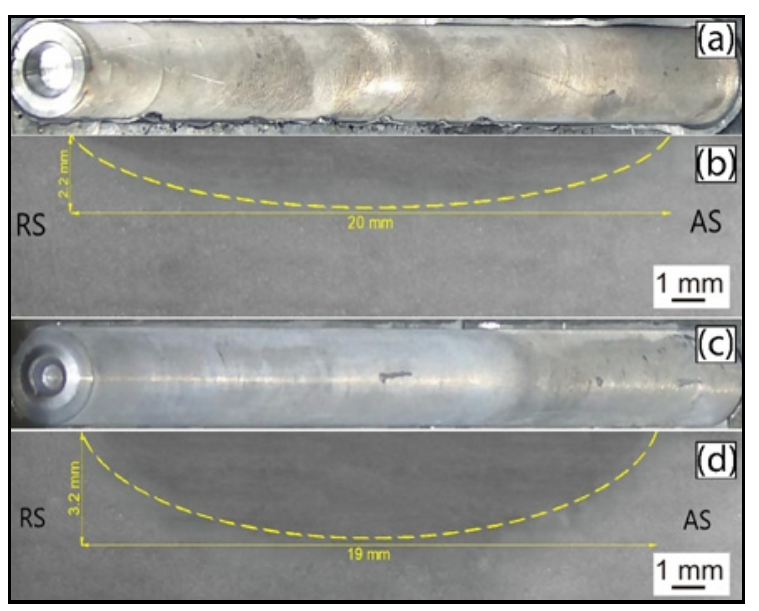

Fig. 3. (a) Top view of air processed sample, (b) crosssection of air processed sample, (c) top view of the underwater processed sample, and (d) cross-section of the underwater processed sample.

S10, respectively. The macrostructure of the sample processed in a particular environment looked alike with minor variation in the width and depth of the SZ. The depth to width ratio (DWR) of the SZ is less affected by the change in processing parameters (rotational speed) than the environment in which it is processed. So here, the DWR of the SZ distinguishes 

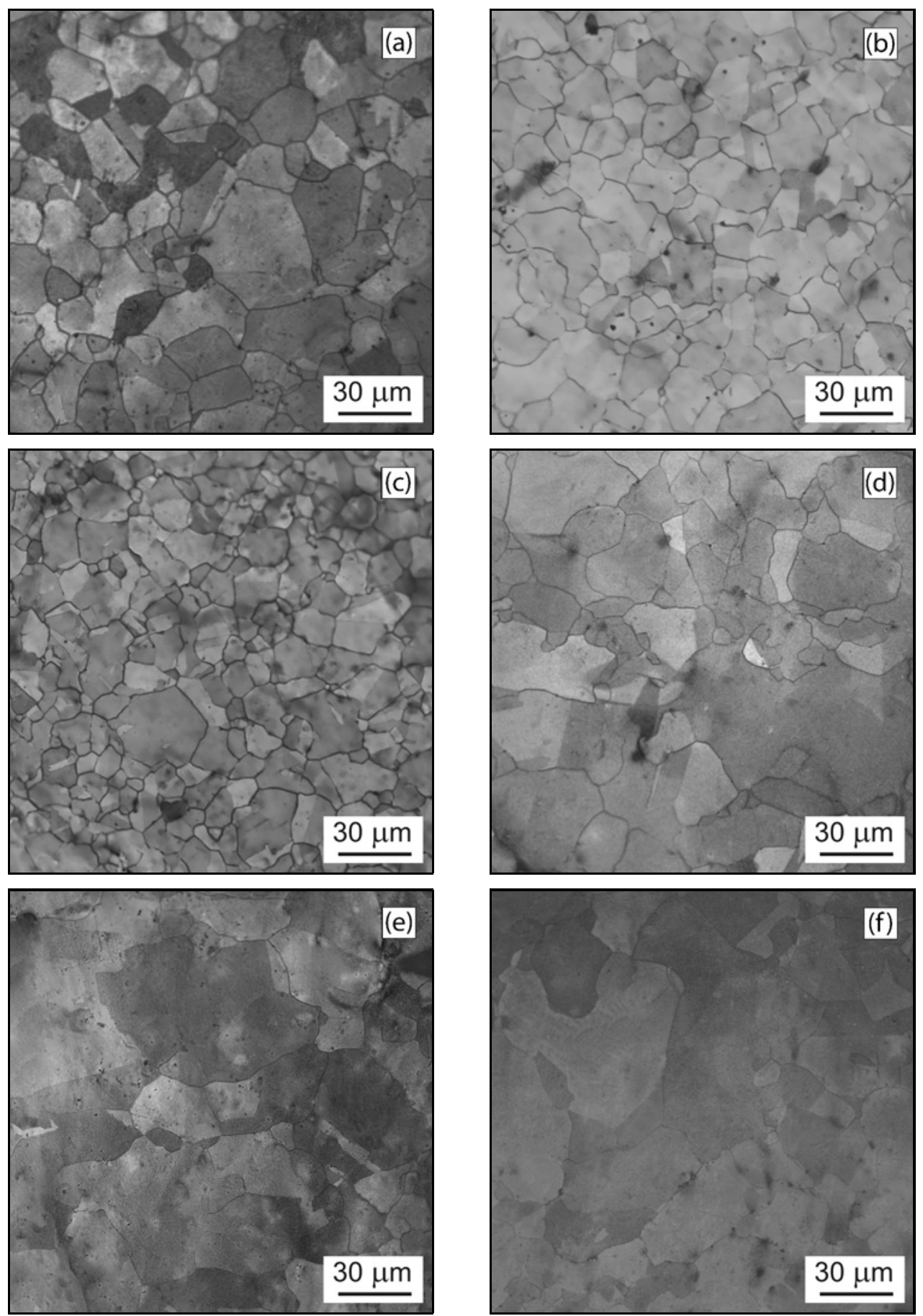

Fig. 4. Optical micrographs of the stir zone for samples processed in air: (a) S01, (b) S02, (c) S03, (d) S04, (e) S05, and (f) base $\mathrm{Pb}$ metal.

the samples processed in air and underwater environment. Generally, the DWR of the SZ mainly depends on the amount of heat generated due to the friction stir processing.

According to the equations given in the literature [35], the amount of heat generated increases with an increase in rotational speed. The equation for heat generation analysis during friction stir welding is given as follows, (Eq. (3)):

$$
Q_{0}=4 / 3 \pi^{2} \mu p N R^{3}
$$

The rate of heat input at the interface between the top of workpiece surface and shoulder is a function of surface radius $(R)$, friction coefficient $(\mu)$, axial load $(p)$, and rotational speed $(N)$. Since the FSP also involves the same parameters (functions), this equation can be utilized here. So, it is expected that the increase in rotational speed leads to enhancement of 
Table 3. Calculated values of the strain, strain rate, and Zener-Hollomon parameter

\begin{tabular}{ccccccc}
\hline Sample & $\begin{array}{c}\text { Avg. grain size } \\
(\mu \mathrm{m})\end{array}$ & APR & Strain, $\varepsilon$ & $\begin{array}{c}\text { Strain rate, } \\
\left(\mathrm{s}^{-1}\right)\end{array}$ & $\begin{array}{c}\text { Deformation temperature } \\
(\mathrm{K})\end{array}$ & $\begin{array}{c}Z \\
\left(\mathrm{~s}^{-1}\right)\end{array}$ \\
\hline S01 & 22 & 0.333 & 8.070 & 0.647 & 454 & 127.885 \\
S02 & 18 & 0.125 & 10.032 & 0.804 & 460 & 148.379 \\
S03 & 12 & 0.077 & 11.003 & 0.883 & 472 & 142.525 \\
S04 & 28 & 0.056 & 11.654 & 0.934 & 487 & 140.145 \\
S05 & 35 & 0.043 & 12.144 & 0.974 & 349 & 134.502 \\
S06 & 17 & 0.333 & 8.070 & 0.647 & 356 & 33.305 \\
S07 & 14 & 0.125 & 10.032 & 0.804 & 367 & 38.314 \\
S08 & 10 & 0.077 & 11.003 & 0.882 & 379 & 37.428 \\
S09 & 5 & 0.056 & 11.654 & 0.934 & 384 & 35.206 \\
S10 & 20 & 0.043 & 12.144 & 0.974 & & 34.994 \\
\hline
\end{tabular}

heat input during the FSP. The DWR showed a slight increase with the increase in the rotational speed in both the environments, which suggested that the heat input had been enhanced and a strong shear force had been induced due to the increase in rotational speed as expected. The DWR for the sample processed in air ranged from 0.098 to 0.11 with the sample S5 showing the maximum DWR. In the case of underwater processing, the DWR showed a whopping increase of $52.73 \%$ to range from 0.154 to 0.168 with the sample S10 exhibiting the maximum DWR. This drastic increase was found due to the presence of a water environment around the sample and shoulder, which helped the heat be more concentrated under the processing tool [26].

\subsection{Microstructure}

Figure $4 \mathrm{f}$ shows the optical micrograph of the base $\mathrm{Pb}$ metal. The average grain size was around $50 \mu \mathrm{m}$. When subjected to FSP, the grain size was refined due to severe plastic deformation. The high strain induced, introduces a high density of dislocation, and these dislocations subsequently rearrange themselves to form grain boundaries, which are responsible for the refinement. It is seen that grain refinement increases and then decreases due to grain growth with the increase in rotational speed. The best grain refinement is seen in sample S03 in air and S09 in underwater conditions. The formation of mechanical twins was observed within the grains. This can be attributed to the large plastic deformation induced to the processed area due to FSP [36]. A mechanical twin is formed so that the grains can reach a minimum energy state [37].

The micrographs in Figs. 4a-e show that grain refinement occurred when $\mathrm{Pb}$ was processed in air. It was inferred from samples S01, S02, and S03 that refinement was better at higher rotational speeds. All the samples showed an inhomogeneous grain structure with the formation of mechanical twins. This is because $\mathrm{Pb}$ has a very low recrystallization temperature, which is generally below $0^{\circ} \mathrm{C}[38]$. This low temperature suggests that the recrystallization is complete in the samples processed in air, and the dislocations are minimum. This complete dynamic recrystallization of the grains reveals an equiaxed microstructure throughout the stir zone. The obtained equiaxed grains were non-uniform throughout the stir zone of all the processed samples. In sample S04, the initiation of grain growth was observed, and the maximum grain growth was achieved in sample S05. This can be attributed to the fact that the heat is not dissipated fast enough in the air, and grain recovery is allowed to take place $[26]$.

Better grain refinement was observed in underwater conditions, as shown in Figs. 5a-e. Similar to the samples processed in air, an equiaxed grain structure was seen throughout the stir zone of the samples processed underwater. Though the recrystallization temperature of $\mathrm{Pb}$ was less, the rate of heat dissipation was higher in underwater conditions, and thus the dynamic recrystallization was not complete. Therefore, it should contain higher dislocation densities, which formed a greater number of grain boundaries which was responsible for the higher grain refinement.

The finer grain structure produced by UFSP is expected to improve the ductility and formability of the samples at elevated temperatures and improve its superplastic behaviour [19]. An increase in the grain refinement is observed with an increase in rotational speed from samples S06 to S09. All of the microstructures show the formation of mechanical twins which are being formed so that the grain structure can reach a minimum energy state. The grain growth was arrested until sample S09, however, for sample S10, due to very high rotational speed, the rate of heat input to the $\mathrm{Pb}$ metal is higher than the rate of heat dissipation. This causes irregular grain growth, which leads to the formation of a bimodal microstructure. The maximum grain size of a bimodal was around $45 \mu \mathrm{m}$, and the minimum grain size was $5 \mu \mathrm{m}$. Since the highly refined grains were in larger quantities, the average grain size was around $20 \mu \mathrm{m}$. The average grain size for the processed samples is reported in Table 3. 

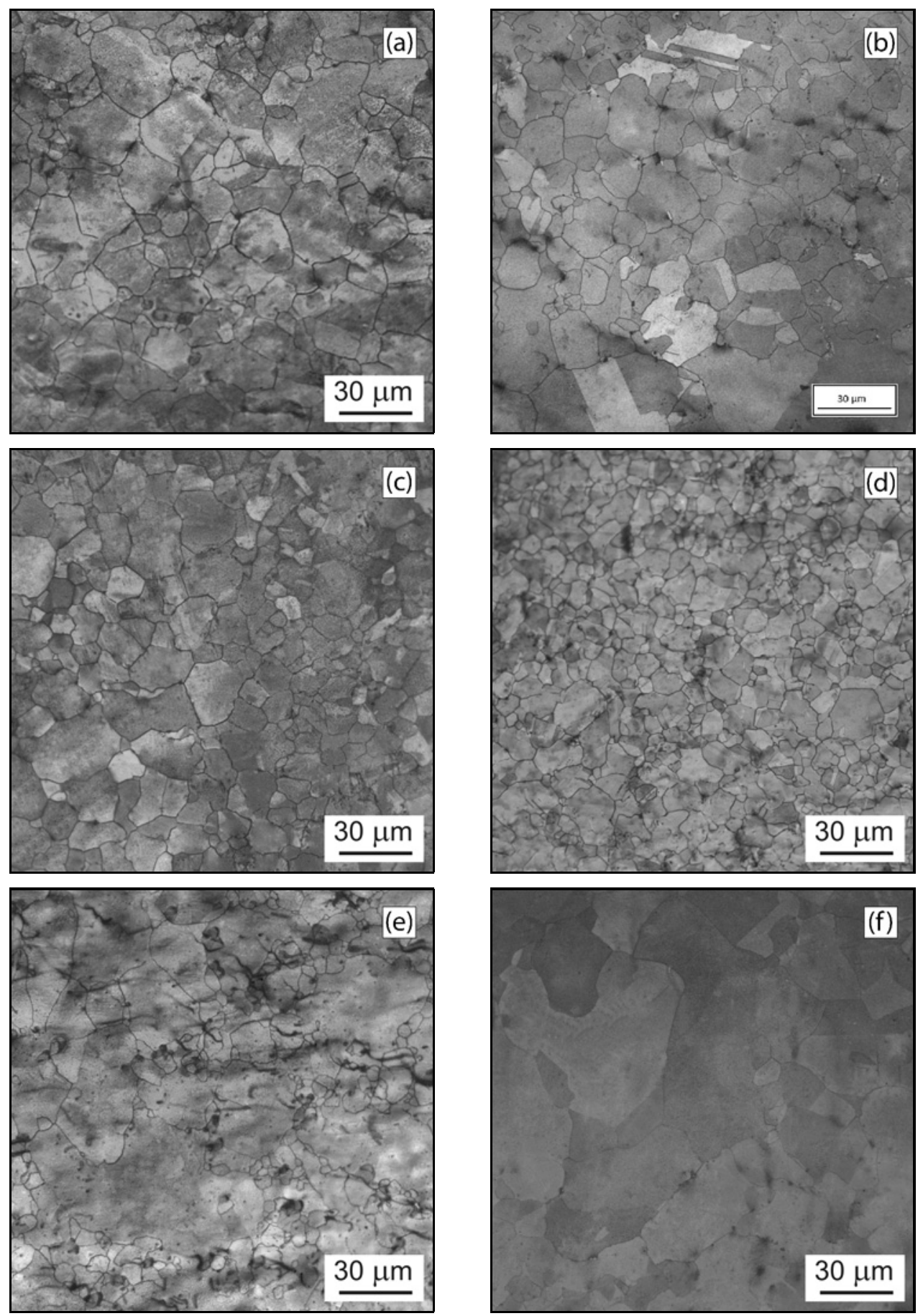

Fig. 5. Optical micrographs of the stir zone for samples processed underwater: (a) S06, (b) S07, (c) S08, (d) S09, (e) S10, and (f) base $\mathrm{Pb}$ metal.

\subsection{Validating the grain size through Zener-Hollomon parameter}

The dynamic recrystallized grain size in FSPed SZ is governed by the Zener-Hollomon parameter. Under severe plastic deformation during FSP, the grain size of the sample depends on the strain rate and the temperature of deformation. These two variables can be expressed by the Zener-Hollomon parameter $(Z)$ as
[39], (Eq. (4)):

$$
Z=\dot{\varepsilon} \exp (Q / R T),
$$

where $\dot{\varepsilon}$ is the strain rate, $Q$ is the activation energy of the process, $R$ is the universal gas constant, and $T$ is the deformation temperature. It is well known that the recrystallized grain size can be estimated by the strain rate $[40,41]$. However, it is difficult to measure 


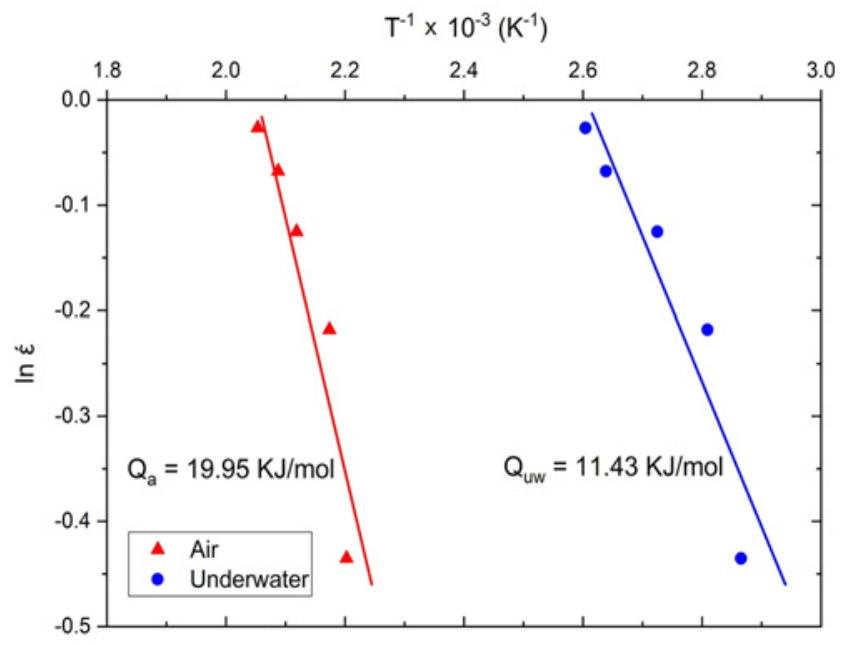

Fig. 6. Arrhenius plot to calculate activation energy.

the strain rate accurately during the FSP because the various changes in the $\mathrm{SZ}$ cannot be observed directly using conventional methods. Therefore, the determination of the strain rate is very important for validating the microstructure in the SZ. The total strain during friction stir welding was expressed as [42], (Eq. $(5))$ :

$$
\varepsilon=\ln (l / \mathrm{APR})+|\ln (\mathrm{APR} / l)|,
$$

where APR is the tool advance per revolution ( $\mathrm{mm}$ $\left.\mathrm{rev}^{-1}\right)$, which is the ratio of tool transverse speed $\left(\mathrm{mm} \mathrm{min}^{-1}\right)$ and rotational speed $(\mathrm{rpm}) ; l$ might be expressed as, (Eq. (6)):

$$
l=2 r \cos ^{-1}[(r-a) / r]
$$

where $r$ is the probe diameter, and $a$ is the distance perpendicular to welding direction from the retreating to advancing side of the tool, i.e., the region over which material was transported in streamline fashion around the pin. As per Reynolds [42], the value of $a$ varies from 0 to $r$ across the weld line. Considering the value of $r=6 \mathrm{~mm}$ and a maximum value of $a=r, l=$ $18.85 \mathrm{~mm}$ for all the samples, the strain rate during processing was [43], (Eq. (7)):

$$
\dot{\varepsilon}=\varepsilon / \sqrt{3} t
$$

where $t$ is the deformation time and related as $t=r / v$, and $v$ is the traversing speed. Substituting the values, the value of $t$ is $7.2 \mathrm{~s}$ for all the processed samples.

The value of the activation energy $(Q)$ of the lead metal, which is necessary to calculate the $Z$-value, is found out using the Arrhenius equation. In Arrhenius plot (Fig. 6), the natural logarithm of the strain rate is plotted against the temperature inverse function.

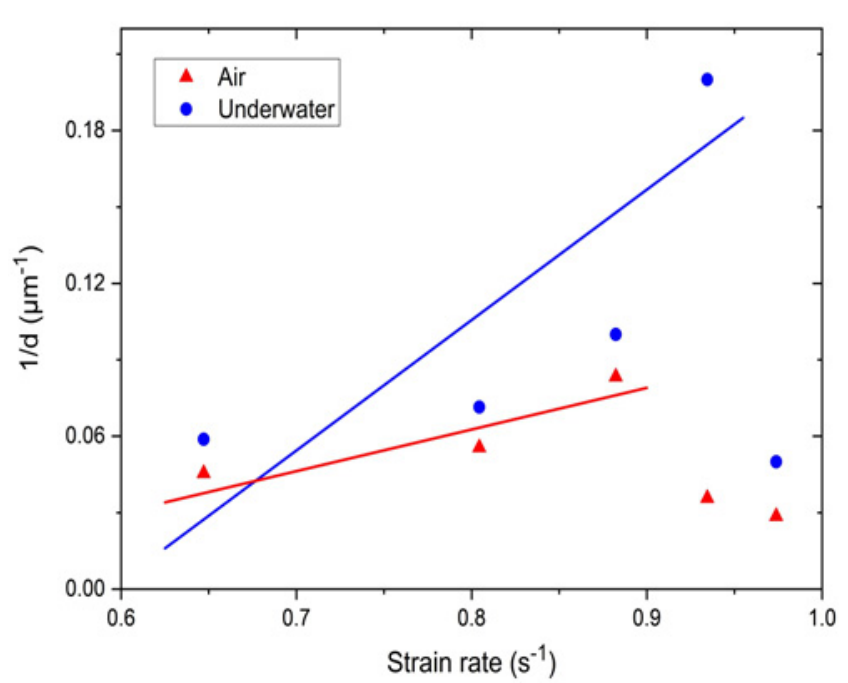

Fig. 7. Relationship between grain size and strain rate during FSP.

The slope of the line in this plot gives the ratio of the activation energy and the gas constant. The values of activation energy of the samples processed in air and underwater are found out from this slope. The activation energy of samples processed in the air was found to be $19.95 \mathrm{~kJ} \mathrm{~mol}^{-1}$ and that of the samples processed underwater was calculated as $11.43 \mathrm{~kJ} \mathrm{~mol}^{-1}$. The calculated values of the strain, strain rate, and the Zener-Hollomon parameter $(Z)$ from the above equations are published in Table 3 .

The relation between the grain size and the strain rate can be found in Fig. 7 . The inverse of the grain size $\left(d^{-1}\right)$ has a linear relation with the strain rate, for the samples which showed grain refinement. However, the samples with revealed grain growth showed some deviation from the linear relation and those points were neglected. In the present investigation, the grain size of the samples processed in air and underwater decreased up to a particular strain rate (S03 for air and S09 for underwater) and then increased as the strain rate increased. The finest grain size for processing in the air (S03) was obtained at a strain rate of $0.883 \mathrm{~s}^{-1}$ and a deformation temperature of around $472 \mathrm{~K}$. In underwater processing, the finest grain size (S09) was obtained at a strain rate of $0.934 \mathrm{~s}^{-1}$ and at a deformation temperature of $379 \mathrm{~K}$. The slope of the line depicting the samples processed underwater was found to be higher than that of the samples processed in air. This shows that the deformation temperature was very much influential in obtaining a highly refined grain size.

The initial $Z$-value for both the processing environments (S01 \& S06) showed the lowest value due to its corresponding low strain value $(\varepsilon)$, which was due to the minimum rotational speed $(150 \mathrm{rpm})$. The $Z$-value 

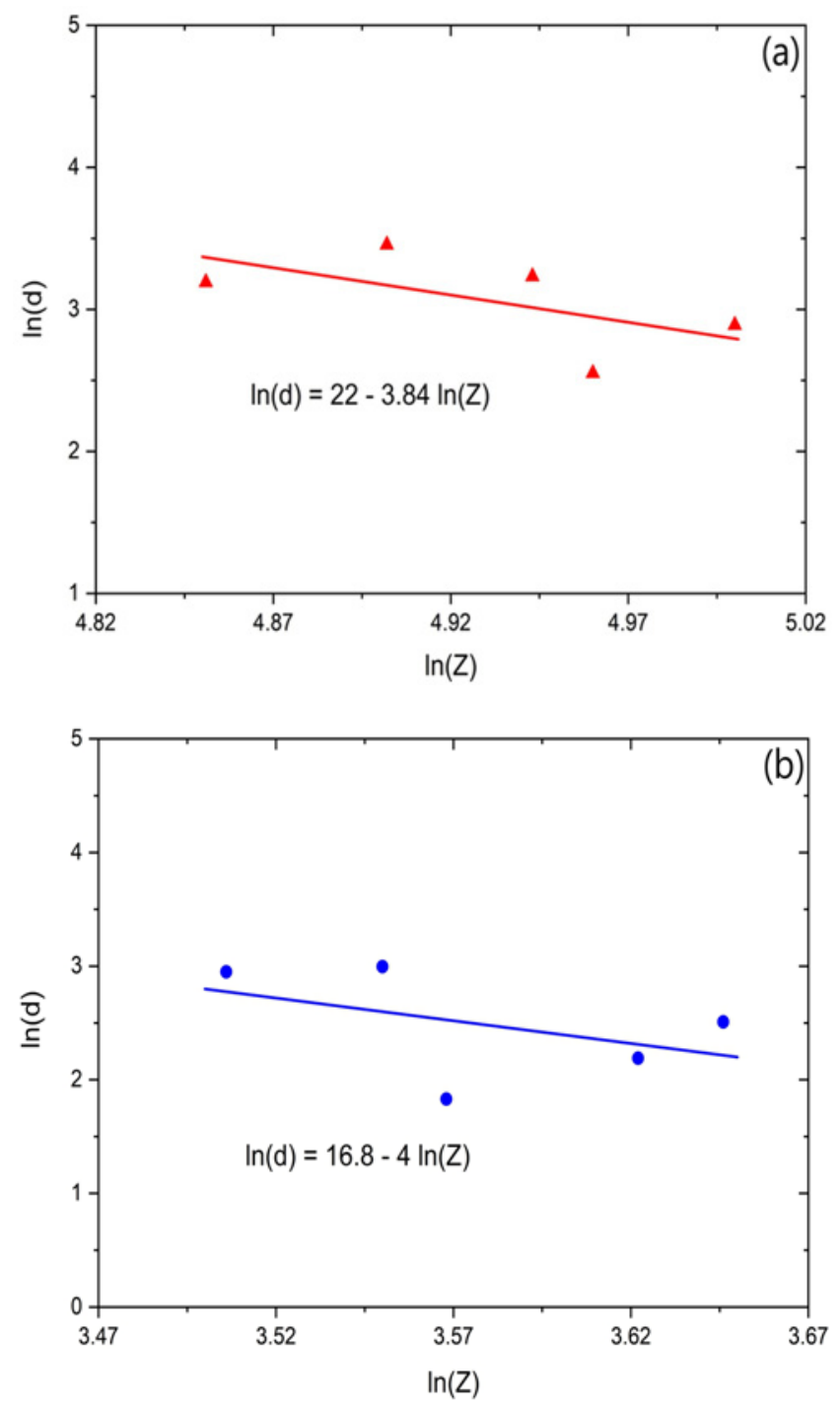

Fig. 8. Relationship between the recrystallized grain size and Zener-Hollomon parameter in specimens processed by FSP in (a) air and (b) underwater.

showed a sudden peak and then decreased gradually. This trend was followed for both the processing environments. Hajian et al. [44] reported that the friction stir processed regions showed highly refined grains for medium to higher $Z$-values. Though sample S02 and S07 showed the highest $Z$-value, they did not have the maximum grain refinement. Further, the samples which had the maximum grain refinement (S03 \& S09) only showed a medium $Z$-value. Therefore, to address the correlation between the Zener-Hollomon parameter and the grain size, the following models were generated. The relationship between the $Z$-value and the average recrystallized grain size $d$ in $\mu \mathrm{m}$ for the lead metal during FSP was established, as shown in Fig. 8. Equations (8) and (9) represent the relationship quantitatively for the samples processed in air and under-

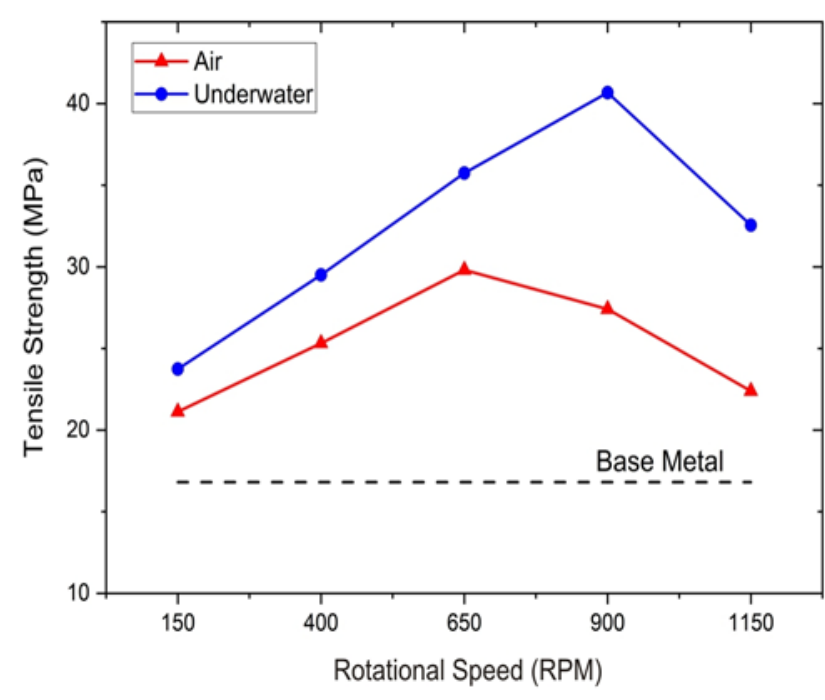

Fig. 9. Variation of tensile strength with rotational speed.

water, respectively:

$$
\begin{aligned}
& \ln (d)=22.0-3.84 \ln (z), \\
& \ln (d)=16.8-4.00 \ln (z) .
\end{aligned}
$$

It should be noted that the range of the values of the $d$ and $z$ of the current study are still narrow; therefore, the uncertainty is higher. The graph implies that the natural logarithm of $Z$ has a linear relationship with the natural log of the grain size. The slope of the underwater sample's graph was higher than the slope of the graph of the samples processed in air. The difference in the intercept and the slope of the linear equations can be attributed to the processing condition and environment.

\subsection{Tensile strength}

The result of the tensile test is published in Table 5. The Ultimate Tensile Strength (UTS) is plotted against the rotational speed (Fig. 9). The UTS of the base metal (pure lead) was measured as 16.81 MPa. The UTS of the samples processed underwater were found to be more than that of the samples processed in air. It is found that the UTS of sample processed underwater increases with an increase in rotational speed until $900 \mathrm{rpm}$. There is a slight dip in the value of the UTS for sample processed in $1150 \mathrm{rpm}$. The UTS of sample processed in the air increased up to $650 \mathrm{rpm}$ and decreased further. This can be explained by relating it to the grain size of the processed samples. As the grain size of the sample decreases the UTS increases and when the grain size increases after a particular strain rate (S03 for air and S09 for underwater) the UTS decreases accordingly. This trend was seen for both air and underwater processed samples. The opti- 
Table 4. Optimum parameters for UTS

\begin{tabular}{cccc}
\hline Sample & Environment & $\begin{array}{c}\text { Rotational speed } \\
(\mathrm{rpm})\end{array}$ & $\begin{array}{c}\text { Tensile strength } \\
(\mathrm{MPa})\end{array}$ \\
\hline S03 & Air & 650 & 29.81 \\
S09 & Underwater & 900 & 40.67 \\
\hline
\end{tabular}

Table 5. Comparison between experimental and analytical tensile strengths

\begin{tabular}{|c|c|c|c|}
\hline Sample & $\begin{array}{l}\text { Experimental tensile strength } \\
(\mathrm{MPa})\end{array}$ & $\begin{array}{l}\text { Analytical tensile strength } \\
\qquad(\mathrm{MPa})\end{array}$ & $\begin{array}{c}\text { Error } \\
(\%)\end{array}$ \\
\hline S01 & 21.12 & 25.34 & -16.66 \\
\hline S02 & 25.32 & 28.02 & -9.63 \\
\hline S03 & 29.81 & 34.31 & -13.12 \\
\hline S04 & 27.41 & 22.46 & 22.02 \\
\hline S05 & 22.39 & 20.09 & 11.44 \\
\hline S06 & 23.73 & 28.83 & -17.69 \\
\hline S07 & 29.51 & 31.77 & -7.11 \\
\hline S08 & 35.74 & 37.59 & -4.92 \\
\hline S09 & 40.67 & 53.16 & -23.49 \\
\hline S10 & 32.55 & 26.58 & 22.47 \\
\hline
\end{tabular}

Table 6. Optimum parameters for thermal conductivity

\begin{tabular}{cccc}
\hline Sample & Environment & $\begin{array}{c}\text { Rotational speed } \\
(\mathrm{rpm})\end{array}$ & $\begin{array}{c}\text { Thermal conductivity } \\
\left(\mathrm{W} \mathrm{m}^{-1} \mathrm{~K}^{-1}\right)\end{array}$ \\
\hline S03 & air & 650 & 22.21 \\
S09 & Underwater & 900 & 14.71 \\
\hline
\end{tabular}

mum conditions for the UTS are tabulated (Table 4).

The UTS of the sample S03 was found to be $77.33 \%$ more the base metal value, while the UTS of S09 showed a drastic increase of $141.94 \%$ from the base metal value. This increase was found due to the refined grain structure and also due to the high dislocation density. The yield stress $\left(\sigma_{\mathrm{y}}\right)$ is related to the grain size $(d)$ through the following Hall-Petch equation, (Eq. (10)):

$$
\sigma_{\mathrm{y}}=\sigma_{0}+k d^{-1 / 2},
$$

where $\sigma_{0}$ is a material constant for the friction stress, and $k$ is a positive strengthening coefficient. According to the Hall-Petch relation [45-47], the ultimate tensile strength (UTS) of a material is proportional to the reciprocal of the square root of grain size, (Eq. (11)):

$$
\mathrm{UTS}=\alpha d^{-1 / 2} \text {. }
$$

Based on this relation, the analytical UTS of all the processed samples were found with the help of the base metal's tensile strength and grain size. It is shown in Table 5. A good linear correlation between the UTS and the inverse of the square root of the grain size $\left(d^{-1 / 2}\right)$ was obtained for lower rotational speeds.
The samples which showed grain growth had a positive error while other samples had negative error.

\subsection{Thermal conductivity}

The results from the thermal diffusivity and the specific heat measurement were used in Eq. (2) to obtain the total thermal conductivity. The thermal conductivity results are tabulated in Table 7 , and the graph is plotted between the rotational speed and the thermal conductivity (Fig. 10). The thermal conductivity of the base metal was found to be $36.7 \mathrm{~W} \mathrm{~m}^{-1} \mathrm{~K}^{-1}$. It can be seen that the thermal conductivity of the samples processed underwater was lesser than that of the samples processed in the air. The thermal conductivity of the samples processed in the air decreased with an increase in rotational speed up to $650 \mathrm{rpm}$ and then increased gradually. However, for samples processed underwater, the thermal conductivity decreased gradually except for the highest rotational speed (S10). This occurrence can be ascribed to the grain size of the processed samples. As the grain size of the sample decreases the thermal conductivity decreases, and when the grain size increases after a particular strain rate, the thermal conductivity increases accordingly. Similar to the ten- 
Table 7. Comparison between experimental and analytical thermal conductivity

\begin{tabular}{|c|c|c|c|}
\hline Sample & $\begin{array}{l}\text { Experimental thermal conductivity } \\
\qquad\left(\mathrm{W} \mathrm{m}^{-1} \mathrm{~K}^{-1}\right)\end{array}$ & $\begin{array}{l}\text { Analytical thermal conductivity } \\
\qquad(\%)\end{array}$ & Error \\
\hline S01 & 28.73 & 24.34 & 18.02 \\
\hline S02 & 23.59 & 22.02 & 7.13 \\
\hline S03 & 22.21 & 17.98 & 23.53 \\
\hline S04 & 23.26 & 27.46 & -15.31 \\
\hline S05 & 26.18 & 30.71 & -14.74 \\
\hline S06 & 23.83 & 21.40 & 11.36 \\
\hline S07 & 20.17 & 19.42 & 3.86 \\
\hline S08 & 17.34 & 16.41 & 5.65 \\
\hline S09 & 14.71 & 11.61 & 26.75 \\
\hline $\mathrm{S} 10$ & 21.09 & 23.21 & -9.14 \\
\hline
\end{tabular}

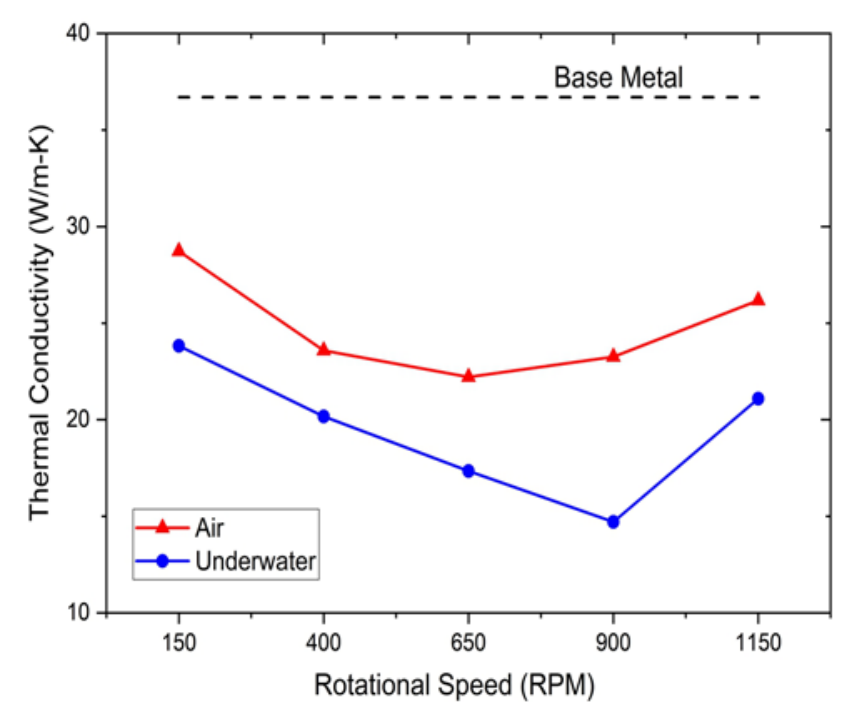

Fig. 10. Variation of thermal conductivity with rotational speed.

sile strength, this trend was seen for both air and underwater processed samples. The optimum conditions with the least thermal conductivity are mentioned in Table 6 .

The optimal thermal conductivity for the samples processed in the air was found to be $39.48 \%$ less than that of the base metal value, while the optimal value for sample processed underwater was around $59.92 \%$ less. This decrease in the thermal conductivity was attributed to the decrease in grain size. Since the samples processed underwater show more grain refinement, their thermal conductivity was found to be lesser than that of the samples processed in air.

Just as in mechanical strength (Hall-Petch effect), the thermal conductivity $k$ is related to the square root of the grain size $(d),($ Eq. $(12))$ :

$$
(k) \propto \sqrt{d} .
$$

Based on this relation, the analytical thermal conductivity of all the processed samples was found. The error between the analytical and experimental results was found and tabulated (Table 7). Though the samples processed underwater showed a lesser error, the samples processed in the air had a higher error percentage. The reason for this occurrence is not known and needs to be further investigated. In both the environments, the highly refined sample showed the maximum error percentage. The samples with grain growth showed a negative error, while all the other samples showed a positive error.

\section{Conclusions}

In this work, the FSP of the pure lead metal was carried out successfully at various rotational speeds and two different environments. The microstructural, mechanical, and thermal properties of the processed samples were investigated. The following conclusions were drawn:

- The DWR was less affected by the change in processing parameters (rotational speed) than the environment in which it was processed. So, it can be used to distinguish the samples processed in air and underwater environment. The DWR was higher for the samples processed underwater due to the higher concentration of the heat. The maximum DWR was exhibited by the sample S10 (0.153).

- The grain size of the sample processed underwater was lesser than that of the sample processed in the air for all the rotational speeds. With an increase in rotational speed, the size of the recrystallized grains decreased.

- In comparison with the samples processed in air, the samples processed underwater showed a higher ultimate tensile strength (UTS) with sample S09 (900 rpm) displaying the maximum UTS (40.67 MPa).

- The thermal conductivity of the samples processed underwater was lesser compared to the thermal conductivity of the sample processed in air, with the sample S09 showing the minimum value $\left(14.71 \mathrm{~W} \mathrm{~m}^{-1} \mathrm{~K}^{-1}\right)$. 
- So, for both thermoelectric and battery applications, the sample S09 showed suitable properties for the maximum benefit. Therefore, UFSP at $900 \mathrm{rpm}$ is the optimum condition for both the applications.

\section{References}

[1] Luo, X., Wang, J., Dooner, M., Clarke, J.: Appl. Energ., 137,2015 , p. 511 doi:10.1016/j.apenergy.2014.09.081

[2] May, G. J., Davidson, A., Monahov, B.: J. Energy Storage, 15, 2018, p. 145. doi:10.1016/j.est.2017.11.008

[3] Yu, C. Y., Sun, P. L., Kao, P. W., Chang, C. P.: Scr. Mater., 52, 2005, p. 359. doi:10.1016/i.scriptamat.2004.10.035

[4] Lugo, N., Llorca, N., Cabrera, J. M., Horita, Z.: Mater. Sci. Eng. A, 477, 2008, p. 366. doi:10.1016/i.msea.2007.05.083

[5] Korn, M., Lapovok, R., Bohner, A., Hoppel, H. W., Mughrabi, H.: Kovove Mater., 49, 2011, p. 51. doi:10.4149/km_2011_1_51

[6] Ueno, H., Kakihata, K., Kaneko, Y., Hashimoto, S. Vinogradov, A.: Acta. Mater., 59, 2011, p. 7060. doi:10.1016/j.actamat.2011.07.061

[7] Valiev, R. Z., Enikeev, N. A., Langdon, T. G.: Kovove Mater., 49, 2011, p. 1. doi:10.4149/km_2011_1_1

[8] Ko, Y. G., Shin, D. H., Park, K. T., Lee, C. S.: Scr. Mater., 54, 2006, p. 1785. doi:10.1016/i.scriptamat.2006.01.034

[9] Palizban, O., Kauhaniemi, K.: J. Energy Storage, 6, 2016, p. 248. doi:10.1016/j.est.2016.02.001

[10] Ibrahim, H., Ilinca, A., Perron, J.: Renew. Sust. Energ. Rev., 12, 2008, p. 1221. doi:10.1016/j.rser.2007.01.023

[11] Bell, L. E.: Science, 321, 2008, p. 1457. doi:10.1126/science.1158899

[12] Kanatzidis, M. G.: Chem. Mater., 22, 2010, p. 648. https://pubs.acs.org/doi/10.1021/cm902195j

[13] Li, J. F., Liu, W. S., Zhao, L. D., Zhou, M.: NPG Asia Mater., 2, 2010, p. 152. doi:10.1038/asiamat.2010.138

[14] Ettinger, A. S., Ruckart, P. Z., Dignam, T.: JPHMP, 25, 2019. doi:10.1097/PHH.0000000000000902

[15] Mishra, R. S., Ma, Z. Y., Charit, I.: Mater. Sci. Eng. A, 341, 2003, p. 307. doi:10.1016/S0921-5093(02)00199-5

[16] Çam, G.: Int. Mater. Rev., 56, 2011, p. 1. doi:10.1179/095066010X12777205875750

[17] Shamsipur, A., Kashani-Bozorg, S. F., Zarei-Hanzaki, A.: Acta. Metall. Sin. Engl. Lett., 30, 2017, p. 550. doi:10.1007/s40195-017-0529-z

[18] Kwon, Y., Saito, N., Shigematsu, I.: J. Mater. Sci. Lett., 21, 2002, p. 1473. doi:10.1023/A:1020067609451

[19] Darras, B. M., Khraisheh, M. K., Abu-Farha, F. K., Omar, M. A.: J. Mater. Process. Technol., 191, 2007, p. 77. doi:10.1016/j.jmatprotec.2007.03.045

[20] Yang, C. W.: Mater. Trans., 55, 2014, p. 371. doi:10.2320/matertrans.M2013344

[21] Alavi Nia, A., Omidvar, H., Nourbakhsh, S. H.: Mater. Des., 58, 2014, p. 298. doi:10.1016/j.matdes.2014.01.069

[22] Raja, A., Pancholi, V.: J. Mater. Process. Technol., 248, 2017, p. 8. doi:10.1016/j.jmatprotec.2017.05.001
[23] Huang, Y. X., Wang, Y. W., Meng, X. C., Wan, L., Cao, J., Zhou, L., Feng, J. C.: J. Mater. Process. Technol., 249, 2017, p. 331. doi:10.1016/j.jmatprotec.2017.06.021

[24] Sree Sabari, S., Malarvizhi, S., Balasubramanian, V.: J. Manuf. Process., 22, 2016, p. 278. doi:10.1016/j.jmapro.2016.03.014

[25] Hoyos, J., Pereira, V., Giorjao, R., McNelley, T. Ramírez, A.: J. Manuf. Process., 22, 2016, p. 82. doi:10.1016/j.jmapro.2016.01.012

[26] Heirani, F., Abbasi, A., Ardestani, M.: J. Manuf. Process., 25, 2017, p. 77. doi:10.1016/j.jmapro.2016.11.002

[27] Hofmann, D. C., Vecchio, K. S.: Mater. Sci. Eng. A., 402, 2005, p. 234. doi:10.1016/i.msea.2005.04.032

[28] Chai, F., Zhang, D., Li, Y., Zhang, W.: J. Mater. Sci., 50, 2015, p. 3212. doi:10.1007/s10853-015-8887-2

[29] Darras, B., Kishta, E.: Mater. Des., 47, 2013, p. 133. doi:10.1016/i.matdes.2012.12.026

[30] Bhadouria, N., Thakur, L., Kumar, P., Arora, N.: Can. Metall. Q., 56, 2017, p. 94. doi:10.1080/00084433.2016.1270394

[31] Cao, G. H., Zhang, D. T.: Mater. Sci. Forum, 816, 2015 , p. 404 doi:10.4028/www.scientific.net/MSF.816.404

[32] Feng, X., Liu, H., Lippold, J. C.: Mater. Charact., 82, 2013, p. 97. doi:10.1016/j.matchar.2013.05.010

[33] Günen, A., Kanca, E., Demir, M., Çavdar, F., Mistikoğlu, S., Çam, G.: Indian J. Eng. Mater. Sci., 25, 2018, p. 26 http://nopr.niscair.res.in/handle/123456789/44448

[34] Kahl, S.: J. Heron., 55, 2010, p. 223. https://heronjournal.nl/55-34/4.html

[35] Frigaard, Q., Grong, Q., Midling, O.: Metall. Mater. Trans. A, 32, 2001, p. 1189. doi:10.1007/s11661-001-0128-4

[36] Zhao, Y., Kai, X., Chen, G., Lin, W., Wang, C.: Pro. Nat. Sci. Mater., 26, 2016, p. 69. doi:10.1016/j.pnsc.2016.01.009

[37] Jin, Y., Lin, B., Bernacki, M., Rohrer, G. S., Rollett, A. D., Bozzolo, N.: Mater. Sci. Eng. A, 597, 2014, p. 295. doi:10.1016/i.msea.2014.01.018

[38] Hotta, S., Matsumoto, K., Murakami, T., Narushima, T., Ouchi, C.: Mater. Trans., 48, 2007, p. 2665. doi:10.2320/matertrans.MRA2007078

[39] Mirzadeh, H.: Kovove Mater., 53, 2015, p. 105. doi:10.4149/km_2015_2_105

[40] Chang, C. I., Lee, C. J., Huang, J. C.: Scr. Mater., 51, 2004, p. 509. doi:10.1016/j.scriptamat.2004.05.043

[41] Gerlich, A., Su, P., Yamamoto, M., North, T. H.: J. Mater. Sci., 42, 2007, p. 5589. doi:10.1007/s10853-006-1103-7

[42] Reynolds, A. P.: Scr. Mater., 58, 2008, p. 338. doi:10.1016/i.scriptamat.2007.10.048

[43] Jata, K. V., Semiatin, S. L.: Scr. Mater., 43, 2000, p. 743. doi:10.1016/S1359-6462(00)00480-2

[44] Hajian, M., Abdollah-Zadeh, A., Rezaei-Nejad, S. S., Assadi, H., Hadavi, S. M. M., Chung, K., Shokouhimeh, M.: Mater. Des., 67, 2015, p. 82. doi:10.1016/j.matdes.2014.10.082

[45] Hansen, N.: Scr. Mater., 51, 2004, p. 801. doi:10.1016/j.scriptamat.2004.06.002

[46] Prasad, M. J. N. V., Chokshi, A. H.: Kovove Mater., 49, 2011, p. 93. doi:10.4149/km_2011_1_93 
[47] Kostikov, V. I., Agureev, L. E., Eremeeva, Z. V.:

Russ. J. Non-Ferrous Metals, 56, 2015, p. 325. $\underline{\text { doi: } 10.3103 / \mathrm{S} 1067821215030104}$ 